\title{
Inclusive Practices for Neurodevelopmental Research
}

\author{
Sue Fletcher-Watson ${ }^{1}$ (D) Kabie Brook ${ }^{2} \cdot$ Sonny Hallett ${ }^{3} \cdot$ Fergus Murray $^{3} \cdot$ Catherine J. Crompton $^{4}$
}

Accepted: 9 March 2021 / Published online: 9 April 2021

(C) The Author(s) 2021

\begin{abstract}
Purpose of Review Inclusive research practice is both a moral obligation and a practical imperative. Here we review its relevance to the study of neurodevelopmental diversity in particular, briefly describing a range of inclusive research models and justifying their use. The review itself is inclusively co-authored with three autistic collaborators and community leaders who all have extensive experience of research involvement.

Recent Findings Drawing on theoretical arguments and specific exemplar projects, we describe six key considerations in the delivery of inclusive research. These are the following: taking the first steps towards inclusive practice; setting expectations; community-specific inclusion measures; inclusion and intersectionality; the role of empowerment; and knowledge exchange for inclusion. Together, these sections provide an illustrated guide to the principles and process of inclusive research.

Summary Inclusive research practice is both beneficial to and a requirement of excellence in neurodevelopmental research. We call for greater engagement in this participatory research agenda from grant-awarding bodies to facilitate not just inclusive but also emancipatory research.
\end{abstract}

Keywords Participatory research $\cdot$ Inclusion $\cdot$ Neurodiversity $\cdot$ Patient and public involvement $\cdot$ Participation

\section{Introduction}

\section{What Is Inclusive Research Practice?}

Inclusive research takes place with members of the relevant population rather than merely happening to or for them [1]. In the study of neurodevelopmental diversity $[2,3]$, it is characterised by the inclusion of neurodivergent ${ }^{1}$ people in empowered and meaningful roles. In this review paper we first describe models of inclusive practice and outline arguments

\footnotetext{
${ }^{1}$ At the end of the paper, we include a short glossary of terms used in this review, like "neurodivergent", that are not yet part of the established scientific literature.

This article is part of the Topical Collection on Autism Spectrum

Sue Fletcher-Watson

sue.fletcher-watson@ed.ac.uk

1 Salvesen Mindroom Research Centre, University of Edinburgh, Edinburgh, UK

2 Autism Rights Group Highland, Inverness, UK and National Autistic Taskforce, Henley-on-Thames, UK

3 Autistic Mutual Aid Society Edinburgh, Edinburgh, UK

4 Patrick Wild Centre, University of Edinburgh, Edinburgh, UK
}

for its use. We then illustrate six key facets of inclusive research in neurodevelopment, drawing on our own experiences and including illustrative examples from the literature.

Arnstein's ladder of participation [4•] provides a rudimentary model for thinking about inclusive research practice. Rudimentary because the linear structure of this framework suggests that practices higher up the ladder are automatically better than those lower down. Rather, we contend that good inclusive practice serves to match the appropriate participatory research model to the topic and methodology being employed. Nonetheless, this model provides an excellent at-a-glance reference for the different degrees of inclusion, and devolved power, that are possible.

Inclusive research is a framework that sits alongside other defining characteristics of a research project-like the methodology, discipline(s) involved, and dissemination methods (Fig. 1). For example, if a project is qualitative and has good public engagement strategies, it is not necessarily also inclusive research. Specific models of inclusive research, described from the point of view of an academic researcher, include:

- Consultation: inviting community members to provide targeted, expert advice on a project at key intervals or in specified areas of responsibility 

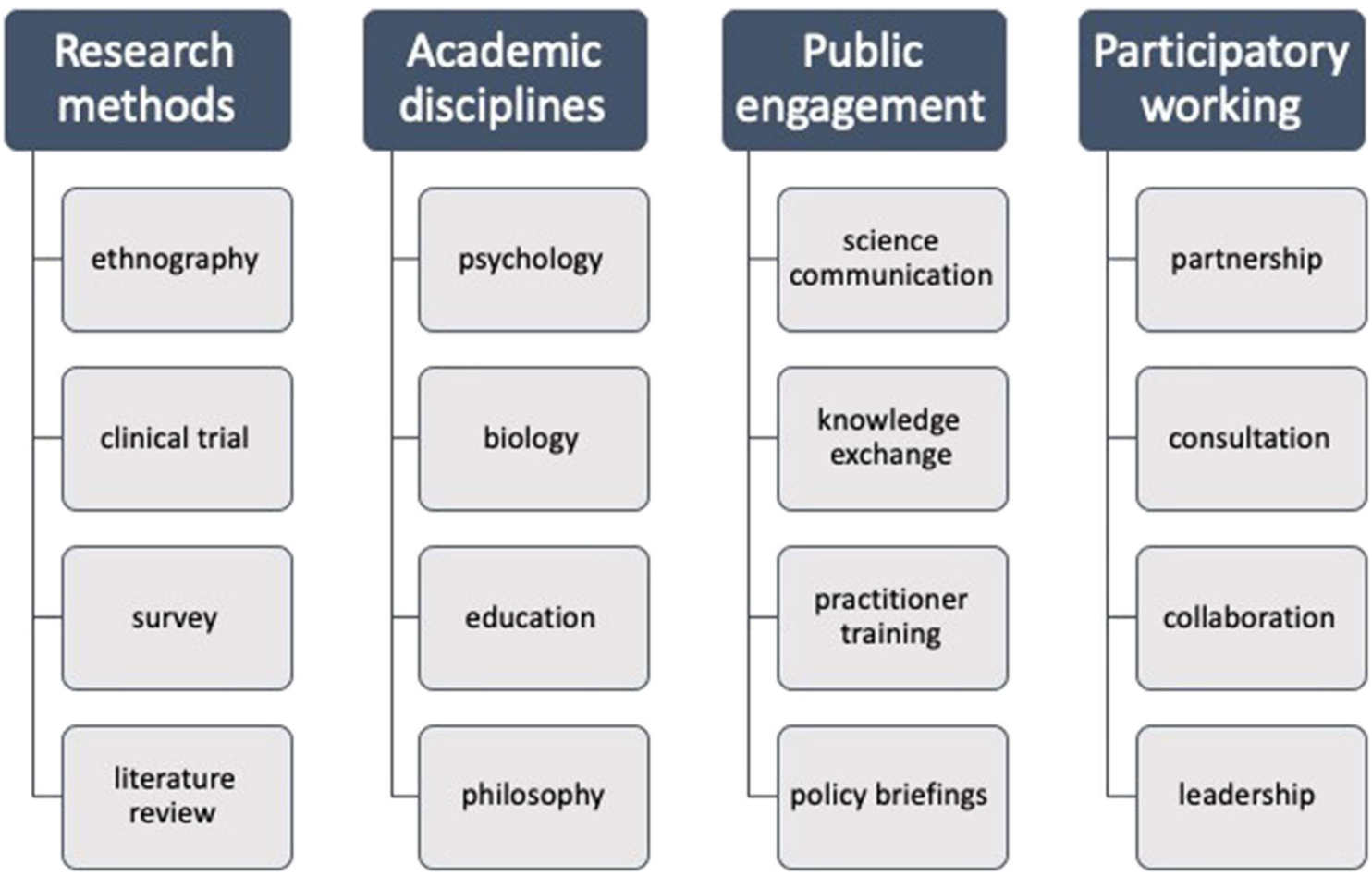

Fig. 1 Selecting a participatory framework, alongside other defining characteristics of a research programme

- Partnership: developing a project which is informed by distinct partners, perhaps having different areas of responsibility, corresponding to their expertise

- Collaboration: working with community members to develop and deliver a project as a team

- Citizen Science: joining with a community-led project to facilitate a research element, or dissemination strategy.

- Leadership: working as an employee or consultant on a project led by community members.

Any and all of these models might fall under the umbrella category of "community-based participatory research" (CBPR; $[5,6])$ which is a collective term for research that happens in and with communities. Said communities may be defined by geography, a common goal, or - as in the case of neurodevelopmental research - a link to a specific neurotype. Community-based participatory research often involves partnerships with groups that have been convened by and are led by community members. The label CBPR may be less applicable to inclusive research that engages with a less coherently organised population. For example, in the study of bilingualism and autism [7] there is no active community of autistic bilinguals and so this research would engage with individual representatives as the primary partners, as well reaching out to community organisations for support.

The chosen inclusive research model will depend on the resources available (on the part of the researcher and their community partner), the scale and probable impact of the research, and where the research is positioned on the pathway from new, fundamental discovery to evaluated and implemented practice. Whilst it might seem imperative to include community representatives in meaningful roles at the point of implementation, in fact, at this stage, many of the key decisions have already been fixed. For example, a community partner sitting on a clinical trial steering committee might have some influence over the choice of outcome measures, design of participant information sheets or interpretation of findings, but it is too late for them to shape the content of the intervention itself. Thus, fundamental science (including social science) may provide the most fertile ground for participatory methods like collaboration, citizen science and community leadership.

\section{Why Is Inclusive Practice Important for Neurodevelopmental Research?}

Research into neurodevelopmental diversity necessarily involves working with minorities, who have been disenfranchised and disadvantaged in many ways linked to their minority status. For example, we know that young people with additional support needs (also termed special educational needs in England, or learning disabilities in the USA) experience higher rates of school exclusion $[8,9]$, social exclusion [10-12] and lower rates of employment [13-15]. People with learning difficulties are also at risk of victimisation and bullying [16, 17], reduced quality of life $[18,19]$, and a range of negative mental health outcomes 
$[20,21]$. There is an increasing (and overdue) recognition of the lifelong nature of neurodevelopmental differences [22], accompanied by research with adult samples which has revealed new kinds of risks. For example, for autistic people, the literature demonstrates high rates of sexual harassment and assault [23], shorter life expectancy [24], and increased prevalence of co-occurring mental illness accompanied by barriers to services [25]. Thus, research in autism, ADHD, dyspraxia, developmental language disorder and so on, frequently involves people who are vulnerable or at-risk.

Researchers have a moral responsibility to provide meaningful and accessible opportunities for people in these groups to share their views and to direct the research that - in the long term-has such a significant impact on their lives [26]. Inclusive research may yield better outcomes by delivering supports or insights that people want, and can use [27]. Not only that, but inclusion in research can itself be a tool to promote better quality of life, by creating new positive relationships between researchers and their community collaborators. Contributing to the generation of knowledge may have positive benefits like feelings of self-esteem and selfdetermination for all involved [28•, 29]. Indeed, for some individuals, the research experience may be not only inclusive but also emancipatory.

Neurodivergence is defined at its core by the fact that neurodivergent people take in external information, and combine, process and respond to it differently from neurotypical people [30]. In other words, in the vast and complex field of neurodevelopmental research, one thing we can all agree on is that neurodivergent and neurotypical people experience the world differently, in both a fundamental and an experiential sense. We cannot possibly hope to increase our understanding of neurodevelopmental diversity without incorporating the perspectives of neurodivergent people [31].

In the sections that follow, we offer a primer on inclusive research practice, aiming to give specific pointers about how to include community perspectives, as well as flagging key considerations in doing so. The guidance is based on our own experiences as a neurodiverse research team from within and beyond academia that has been steadily increasing our inclusive practice over the past 5-10 years. Our arguments are illustrated by examples largely drawn from the autism research field, but clearly applicable to the neurodevelopmental research field much more broadly.

\section{Who to Approach, and How?}

Inclusive research practice requires the inclusion of people who have lived experience of the neurotype being researched [32••]. This should always mean adolescents or adults of that neurotype - dyslexic people, people with ADHD etc., as appropriate to the research question. There are no exceptions to this rule.
Researchers may sometimes query the need to involve autistic adults in, for example, fundamental biological research that takes place entirely in a wet lab, an online survey of teachers, or development of a support programme for preschoolers. In response, we point out that when research is going to be talking about autism and autistic people (or any other population of interest), then the principle of Nothing About Us Without Us applies [33]. If the work hopes to have an impact on the lives of autistic people in the future, whether by developing new medications or teaching practices, then autistic people must be included to ensure any new knowledge is relevant, respectful, and useful to them. Neurodivergent children grow up to be neurodivergent adults, and as such neurodivergent adults should always play a role in developing work relevant to neurodivergent children and their families.

Where children are the focus, they should also be involved to the greatest extent possible and the same applies to the inclusion of people with intellectual disability of any age. These groups will require specific adaptations to enable their inclusion (detailing such measures is outside the scope of this review, but see $[34,35]$ for examples of this in action) and their input will not always be required, depending on the research topic. For example, an inclusive research study about ideal workplace support for autistic adults would not require input from autistic toddlers, but an inclusive research study about ideal nursery support for autistic toddlers would require input from autistic adults.

In addition, other stakeholder groups may make essential contributions - parents, siblings, romantic partners, friends, employers and practitioners in a range of contexts are all welcome collaborators in an inclusive research setting. Many people will belong to multiple relevant categories, for example being neurodivergent and the parent of a neurodivergent child, and they can provide added value by virtue of their multiple perspectives. When research focuses on those who experience barriers to self-advocacy (such as children, and people with intellectual disability), these stakeholders are particularly important. However the inclusion of these representatives should be additional to, and not a substitute for, the voices of people with direct lived experience of the neurotype being studied. When attempting to represent the perspective of, for example, an infant who is known to be likely to receive an autism diagnosis in later life, the point of view of parents, paediatricians, and older autistic people are all of value. They are all members of a community of proxy representatives of the infant, and people invested in the outcome of the work. One example of this at work was an international survey of the autism community - including autistic people, parents of autistic children and practitioners - to establish their attitudes to early autism research with infant cohorts [36]. The survey revealed both important areas of consensus and key distinctions between these stakeholder groups, highlighting the need to incorporate multiple perspectives. 
Making connections with the right people can be hard, however. An excellent starting point is to reach out to community organisations, ideally created and led by people with lived experience of the phenomenon being studied. For example, in their research on the mental health experiences of autistic young people, Crane and colleagues worked with the myVoice team of autistic young people in a communitybased participatory-research framework [37•]. Such communities may exist in online spaces, such as Reddit or Facebook, or be defined by a community-developed hashtag on twitter. It is important to make an approach carefully and explicitly, so that people do not feel their peer group has been infiltrated or exploited, and they can choose to engage with the researcher.

\section{Setting Expectations}

One of the most common reasons why attempts at inclusive practice fail is that the disparate partners in the endeavour do not share an understanding of their roles and responsibilities [38••]. Therefore, an essential part of inclusive research practice is the setting of clear expectations, which do not overpromise in an effort to engage the community. A partnership will always be constrained on both sides, and provided both parties have shared goals and a commitment to honesty and transparency, these can be used to promote, rather than prevent, effective co-working. For example, a recent investigation of the support needs of autistic people as they age involved a diverse group of stakeholders including middleaged and older autistic adults, siblings and children of older autistic adults, and practitioners from a range of disciplines. This approach resulted in the publication of research priorities and creation of a new interview schedule [39, 40]. The research team utilised the Participatory Autism Research Starter Pack (https://issuu.com/crae.ioe/docs/cranestarterpack_pages_v5), which supported them to create a shared understanding amongst the stakeholders, to create an enabling environment, and to make a clear strategy to achieve shared goals. Additionally, we attribute the success of the work to the close, shared focus of all stakeholders on a specific research topic: supporting autistic people as they age.

Before making a first approach, the researcher should share a website, document, or other accessible resource that people can explore to find out more about the research group or specific project. Ideally, neurodivergent people are involved from the first idea, before funding is sought and won, in which case this content may focus on the group's ethos, and research themes being studied, rather than on a specific project. Researchers should also provide a sense of the constraints imposed by the funder, and the likelihood of success of being awarded funding. An example of effective expectation setting comes from an autism research priority-setting exercise delivered in the UK by third sector organisations [41]. The James Lind Alliance uses a standardised and transparent method to work with communities to generate and prioritise key questions, which is grounded in evidence-based practice for the development of community-led priorities [42, 43]. The fact that this methodology is detailed in a comprehensive manual [44] provides all parties with clarity on the process and their role within it.

A final important piece of information to share are clear terms and conditions for the involvement of neurodivergent people. Details might include: the availability of funding for the role, the time commitment involved, both in terms of total project duration and frequency of contact and the format by which community members can contribute (i.e. attending meetings, by email, by skype etc.). It should be clear what are the key elements over which the community can have an influence, and the degree of "editorial" control being offered to the community member, both in terms of within-project decision-making and as a contributor to final outputs including journal articles. In a sequence of studies that aimed to investigate experience of suicidality in autistic people, community representatives exposed problems with existing quantitative measures $[45,46]$ and were invited to review candidate items for an amended measure, and add new items, to improve capture of suicidality in the autistic population [47]. This kind of targeted consultation is ideal in projects like the development of a new measure that also have to follow a very prescriptive process in order to meet scientific quality criteria. Satisfaction of all parties in the end result of the work rests on accurate communication of the goals and remit of the study from the outset.

It is important to note that the burden of expectation setting is very much on the researcher. Community partners may not necessarily have much experience of research, or even undergraduate study. Therefore, they are not in a strong position to set their own terms at the start of a collaboration. Researchers should support their community partners to fully understand and engage with the context of the collaboration, and should provide opportunities to re-visit any agreements as the project evolves and the connection matures. Such terms should ideally also include information on what to do if the partnership breaks down - which may happen due to lack of resource or life events, even when the relationship is amicable and productive. Bigby and Frawley share a frank and inspiring account of co-production with a co-researcher with an intellectual disability [48]. They provide a range of examples of how their terms of reference failed to match the expectations and wishes of the co-researcher, and then describe the adaptations put in place to overcome this.

Setting up the first community connections is much harder than maintaining an inclusive research strategy. Once you have participatory practice established, even on a modest scale, it becomes relatively easy to grow from this base. For example, collaborators in paid roles on an existing funded project can provide informal advice on new ideas as they 
begin to germinate, and also act as gatekeepers into the broader community. In one innovative example, Burke and colleagues [49] describe inviting leaders from an existing inclusive research project to speak to a community audience at a one-day event, which was also then used as an opportunity to recruit co-researchers to their new piece of research. A key determinant of success will be to make contact with people invested in the specific topic of your research, with whom you can build a relationship and a research strategy. Our advice is to start small, and commit to growing your inclusive practice.

\section{Community-Specific Inclusion Measures}

Different communities will experience different kinds of barriers to effective participation in research. In the autistic community for example, research spaces may be uncomfortable from a sensory perspective since autism entails sensory hyper and/or hypo-sensitivity across domains [50]. The communicative and interactive frameworks in which much research is conducted, such as group meetings or conference calls, may be an additional barrier [6].

Other communities will experience different specific barriers to inclusion. For example, reliance on written material may be a problem for some, whilst travelling to in-person meetings may be an issue for others. Where a community partner expresses a clear preference this should be explicitly sought and integrated wherever possible. For example, the Living Life to the Fullest project working with disabled young people deploys almost entirely online communication tools to enable participation [51]. If you are studying a group who are under-represented in higher education, then you need to make sure you have extra measures in place to ensure they feel comfortable with the setting and vocabulary of Universitybased research. The researcher has a responsibility to understand the community with whom they hope to collaborate, and to tailor their approach to the needs and preferences of that community [52•].

\section{Inclusion and Intersectionality}

A corollary to the point made immediately above, is to note that someone's diagnostic status is not their only, or even prime, identifying characteristic. Our research team's work largely focuses on understanding autism and using this knowledge to make improvements in autistic people's lives. This means that autistic people are the key stakeholders in our research. However, these people are not only autistic - an obvious fact and yet an easily forgotten one. Our autistic collaborators may be parents, entrepreneurs, practitioners, tenants, and activists. They navigate the challenges that come with an autistic identity, but may also experience privilege, or intersectional disadvantage, via other key characteristics. The value of an intersectional approach, that takes account of multiple intersecting identities and the advantages/disadvantages that these entail [53], is prominent in autism research for two key reasons. First, we know that autistic people are more likely than the general population to identify as non-heterosexual, and outside the gender binary $[54,55]$. Second, we know that black and minority-ethnic autistic people face specific combinations of discrimination as a result of their race and diagnostic status [56-58] and yet are under-represented in research [59].

These issues bring a consideration of complex elements of identity to the fore in autism research, but intersectionality matters in the study of any element of neurodevelopmental diversity. This is made even more pressing by the context of more general problems regarding equality and diversity within academia, such as gender inequality and discrimination against people from the LGBT+ community [60, 61]. When developing inclusive research practice, researchers must remember to recognise and account for intersectionality in the recruitment of, and support provided to, community research partners. They should consider and, if possible, report on diversity in both their participant samples and their community research partners. Aspects like the timing and location of meetings, catering available at events, and the default pronouns used in project materials, should be inclusive of the ethnicities, religions, physical abilities, genders and neurotypes of people taking part.

Intersectionality is also a key reason why even neurodivergent researchers ought to consider participatory working, in order to be confronted with perspectives different to their own. Inevitably, teams cannot, in one specific project context, represent all the elements of identity that influence the phenomenon under investigation. Researchers need to be willing to consider views other than their own, to consider who is not present in the room when key decisions are being made, and to directly address why certain perspectives could not be accommodated in a specific situation. Transparency and honesty regarding these considerations are an essential part of inclusion.

\section{The Role of Empowerment}

Inclusive practice requires that community members are not only invited to join research teams, but also enabled to play an active role [62・0]. In ideal circumstances, participation as a coresearcher is valuable and positive in and of itself - as reported from a recent survey of 240 participants in a co-produced research seminar series "the processes and experiences of engagement and participation were valued as much as (if not more than) any possible, more formalised, indications of 'outcomes" [63]. However, community members can have their ability to contribute limited by a range of factors such as the use of technical jargon, the researcher controlling the flow of information $[62 \bullet \cdot$, and not feeling that their contribution is 
properly valued [64]. This latter may be especially likely if a community partner is youthful, or has an intellectual disability, or has fewer educational qualifications than the research team.

One way to promote empowerment for community partners is to provide adequate payment for their time, at consultancy (rather than research participant) rates. Meetings at which only some people are paid to be there are not best inclusive practice. Payment explicitly values expertise by lived experience, and means that joining a research team is more likely to be framed as a right, rather than as a privilege [32••]. Payment should ideally be in the form of a consultant salary (whether paid regularly or as a one-off) but researchers should engage in a dialogue with collaborators and aim to provide a form of payment that suits their personal circumstances. For example, in the UK and other countries, many autistic people may receive state welfare support, which can make it challenging to accept fair payment for consultancy [32••]. Whilst a limited amount of consultancy income is usually permitted, the bureaucracy and scrutiny involved in demonstrating this may be unacceptable or excessive. Relatedly, Black and colleagues describe challenges making payments to Community Experts using institutional systems not set-up for this purpose [65]. This might mean agreeing to make payment in vouchers or in kind, in order to bypass bureaucratic challenges.

Furthermore, lack of funding does not have to prevent inclusive research from happening at all. Many neurodivergent people will lend their time to unpaid roles, just as we all choose to volunteer our expertise to causes that we care about. In such cases - e.g. small scale student projects - the input requested from neurodivergent people should be appropriately scaled and low impact for them. For example, consultation via short social media polls or video/phone conversations may be possible and still add value.

Another important mechanism to ensure that people are empowered to act within a partnership is the aforementioned expectation-setting exercise. This should be developed and enriched with detail as the partnership takes shape. Clarity on the remit an individual has within a project team can help them understand when it is appropriate to push for change. Researchers who aim to include community representatives in their work need to demonstrate a willingness to make changes when these are requested, and a commitment to transparent articulation of their reasons if they feel change is not warranted or possible [29]. Expectation setting should also include information about how conflicts can be resolved (e.g. is this a democratic process or does the principal investigator have the final say?) and how contributions will be recognised [6]. We highly recommend collaborative analysis, interpretation and co-authorship of project outputs as a valuable way to reduce power disparities and deliver equality, as in this example reporting on autistic social experiences [66].

\section{Knowledge Exchange for Inclusion}

Research is rife with technical language and specialist knowledge that acts as a barrier to inclusion. There is a significant risk that the most rarefied fields of enquiry simultaneously have greatest potential to shape future practice, whilst also being the least amenable to inclusive practices [67]. One example would be research exploring the development of a polygenic risk score for autism. Inclusion of autistic people in this fundamental scientific discovery process is necessary to ensure that communication about the work is respectful to that community, and that ethical debates about potential applications of such a discovery (for example, in pre-natal testing) are informed by knowledgeable autistic people from the outset [68]. Science communication is important to help people outside academia grasp the relevant genetic and statistical concepts, so that they can become more informed consumers of research. However, we would also argue that more targeted information ought to be directed into the relevant stakeholder groups, so that they can not only understand the work but also so be involved in its delivery.

We can achieve this goal without "dumbing down" science by up-skilling community partners, making each participatory project a knowledge exchange process. For example, in the Family in Residence project the Patrick Wild Centre worked with twin boys with fragile $\mathrm{x}$ syndrome and their parents over the course of a year, to evaluate how we do research at both biological and clinical levels (https://patrickwildcentre.com/ family-in-residence/). The family visited the laboratory spaces, and scrutinised our trial materials including information sheets, consent forms and a range of commonly used outcome measures. In return, our team gained valuable insights into their lives and the project continues to shape practice in the Centre. More recently, we delivered a Research 101 training course for autistic people in our local community, aiming to support them to become more Informed Consumers of research, Empowered Participants in research projects and Effective Collaborators in inclusive research contexts (http://dart.ed.ac.uk/research/learning-aboutresearch).

Whilst knowledge exchange models are an important component of inclusive research, academics can also make an effort to specifically locate and recruit community partners with specific expertise in the discipline and methods of the project. Building relationships with such collaborators helps with the development of a shared knowledge based and vocabulary. Long-term connections also build trust, which enables both parties to take more risks in what they share and how they express their opinions. Both trust and shared knowledge promote fruitful debate [36]. However, at the same time, researchers should guard against working with a selected group of community representatives over a very long period, where all parties become bought-in to a shared agenda. One 
function of inclusive research is for team members to be confronted with perspectives other than their own, and this value may dissipate over a long partnership which becomes an echo chamber.

\section{Looking Ahead}

Here we have outlined key considerations when including people with lived experience of neurodevelopmental diversities in the research process. We hope that this paper can be a primer for people who are curious about inclusive research practices, providing both a motivation and a practical guide to delivering inclusion.

Although we have cited examples from the literature, we also note that reporting of inclusive practices remains limited and variable [69]. It is challenging to find examples of participatory research even when these practices have been followed: descriptions of participatory practice tend to consist of a short statement in the methods of a paper, including in the work of the current authors. Journals rarely invite detail on this element of the work and knowledge about participatory research practices remains largely tacit and hidden. Additionally, there is vanishingly little work that empirically demonstrates the practical benefits of inclusive practice for research in neurodevelopment. Likewise, benefits to neurodivergent community co-researchers have been described qualitatively (e.g. [62・•]), but rarely-if-ever quantified, or characterised over the longer-term.

Because inclusion is a matter of moral principle, rather than a tool to increase effectiveness, we reject the notion that evidence of the impact of inclusion on research outcomes is a prerequisite for use of inclusive practices. As a parallel, consider the requirement of informed consent. We do not ask whether informed consent makes research better, in the sense of more effective or impactful - rather we accept the principle of informed consent as an essential criterion of good research, regardless of outcome. This does not mean that evaluation of inclusive practices is never relevant or welcome. Evaluations can help us understand the best way to engage with communities, and to chart benefits (e.g. more effective implementation of a co-designed intervention than one without community input), thus leveraging greater investment in inclusive working. In the future, improved reporting of inclusive practices and evidence of their effectiveness - including feasibility and acceptability—would be welcome.

For research to become fully inclusive-perhaps even emancipatory - will take more than the energies of individual investigators. We believe that grant funders should more explicitly recognise the importance of inclusive research practice in this field, for example, by encouraging researchers to cost for community consultants on a grant as standard, and by providing effective mechanisms to make these payments [65]. Proposal forms should include specific sections inviting applicants to describe how people with lived experience have been and will be involved in the work. There are models for this work [70], including Involve [71] which supports public involvement in UK health research, and the Charles Sharland grants scheme by Autistica, which provides funding for autistic-led research [72].

As a research community, we need to develop and disseminate innovations in participatory research-for example to facilitate the meaningful inclusion of young children and people with intellectual disabilities. Universities should offer training in participatory research methods within degrees and as continuing professional development. Again, there is an effective model already, in the many forms of support for public engagement skill development and delivery that already exist. Throughout all of this, higher education institutions and society in general needs to continue to work towards elimination of educational and health disadvantages that disproportionately and unfairly affect neurodivergent people, so that in the future we can start to see more leadership of research within neurodiverse research teams.

\section{Conclusion}

Our experience has been that including community members in the development, delivery and dissemination of a project builds positive relationships and trust between researchers and the community - as evidenced by the co-production of this review article. Ongoing dialogue between academic researchers and community members on social media, by email, video conferencing and in person is now a daily feature of our team. Pleasingly, there is little or no distinction in how our work is discussed when exclusively amongst those employed as academics, versus with our colleagues outside our institution. We highly recommend adopting inclusive practices, not only to achieve better outcomes in research, and for our society, but also for an enriching, fascinating and enjoyable research process.

\section{Glossary}

Neurodiversity We use this term to refer to the phenomenon of diversity in neurology (including brain structure, connectivity, and function) that is a feature of the human race. In this paper, we also use the term "neurodevelopmental diversity" as a more accessible label for the same concept, whilst also emphasising developmental processes. Whilst each person differs individually from the next, neurodiversity also gives rise to those differences in brain processes, and therefore in experience and behaviour that underpin categories such as autistic/non-autistic. An individual alone cannot be neurodiverse, but a group of people may be neurodiverse if they differ in their neurotype. 
Neurodivergent We use this term to describe people whose underlying brain processes give rise to a categorical distinction from the majority norm in both experience and behaviour. Neurodivergent is a useful collective term that encompasses a large range of people who are commonly the focus of research in neurodevelopment. Autistic, dyslexic and dyspraxic people as well as people with ADHD, DLD or Tourette's syndrome may all be described as neurodivergent, though this list is not exhaustive, and as individuals they may not necessarily choose to self-describe in that way.

Neurotype We use this term to refer to the category distinctions that separate different neurodivergent and neurotypical people, without needing to list specific diagnostic examples each time. For example, amongst the authors of this paper, two neurotypes are represented because three authors are autistic and two are neurotypical. We recognise that such categoryboundaries are socially constructed, shift over time and that members within a category are not homogenous.

Neurotypical We use this term to refer to the majority neurotype that might otherwise be labelled "typically-developing" or "typical" in a lot of neurodevelopmental research. Neurotypical people differ from each other at an individual level, just as is the case for autistic people or any other neurotype. Nonetheless, we consider neurotypical to be a useful term to describe the dominant neurotype. Neurotypical people are often recruited as a "comparison group" in neurodevelopmental research.

\section{Compliance with Ethical Standards}

Conflict of Interest Sue Fletcher-Watson reports grants from Autistica outside the submitted work and also reports that she is the sister-in-law of Mr. Jon Spiers, former Chief Executive Officer of Autistica. Kabie Brook reports grants from Autistica outside the submitted work. Catherine Crompton reports grants from Autistica outside the submitted work. Sonny Hallett and Fergus Murray declare no conflicts of interest relevant to this manuscript.

Human and Animal Rights and Informed Consent This article does not contain any studies with human or animal subjects performed by any of the authors.

Open Access This article is licensed under a Creative Commons Attribution 4.0 International License, which permits use, sharing, adaptation, distribution and reproduction in any medium or format, as long as you give appropriate credit to the original author(s) and the source, provide a link to the Creative Commons licence, and indicate if changes were made. The images or other third party material in this article are included in the article's Creative Commons licence, unless indicated otherwise in a credit line to the material. If material is not included in the article's Creative Commons licence and your intended use is not permitted by statutory regulation or exceeds the permitted use, you will need to obtain permission directly from the copyright holder. To view a copy of this licence, visit http://creativecommons.org/licenses/by/4.0/.

\section{References}

Papers of particular interest, published recently, have been highlighted as:

- Of importance

- Of major importance

1. Israel BA, Eng E, Schulz AJ, Parker EA. Introduction to methods in community-based participatory research for health. Methods Commun-Based Participatory Res Health. 2005;3:26.

2. Arnold L. A brief history of "Neurodiversity" as a concept and perhaps a movement. Autonomy. 2017;1(5).

3. Kapp SK, Gillespie-Lynch K, Sherman LE, Hutman T. Deficit, difference, or both? Autism and neurodiversity. Dev Psychol. 2013;49(1):59-71.

4. Arnstein SR. A ladder of citizen participation. J Am Inst Plann. 1969;35(4):216-24 This classic text provides the basis of many more recent approaches to inclusive research practice.

5. Israel BA, Schulz AJ, Parker EA, Becker AB, Allen AJ, Guzman $\mathrm{JR}$, et al. Critical issues in developing and following CBPR principles. Commun-Based Participatory Res Health. 2017:32-35.

6. Nicolaidis C, Raymaker D, McDonald K, Dern S, Ashkenazy E, Boisclair C, et al. Collaboration strategies in nontraditional community-based participatory research partnerships: lessons from an academic-community partnership with autistic self-advocates. Prog Community Health Partnersh. 2011;5(2):143.

7. Digard BG, Sorace A, Stanfield A, Fletcher-Watson S. Bilingualism in autism: language learning profiles and social experiences. Autism. 2020;24(8):2166-77.

8. Paget A, Parker C, Heron J, Logan S, Henley W, Emond A, et al. Which children and young people are excluded from school? Findings from a large British birth cohort study, the Avon Longitudinal Study of Parents and Children (ALSPAC). Child Care Health Dev. 2018;44(2):285-96.

9. Parker C, Whear R, Ukoumunne OC, Bethel A, Thompson-Coon J, Stein K, et al. School exclusion in children with psychiatric disorder or impairing psychopathology: a systematic review. Emot Behav Diffic. 2015;20(3):229-51.

10. Arakelyan S, Maciver D, Rush R, O'Hare A, Forsyth K. Community-based participation of children with and without disabilities. Dev Med Child Neurol. 2020;62(4):445-53.

11. Bates P, Davis FA. Social capital, social inclusion and services for people with learning disabilities. Disabil Soc. 2004;19(3):195-207.

12. Garrote A, Dessemontet RS, Opitz EM. Facilitating the social participation of pupils with special educational needs in mainstream schools: a review of school-based interventions. Educ Res Rev. 2017;20:12-23.

13. Adelman PB, Vogel SA. College graduates with learning disabilities - employment attainment and career patterns. Learn Disabil Q. 1990;13(3):154-66.

14. Law J, Rush R, Schoon I, Parsons S. Modeling developmental language difficulties from school entry into adulthood: literacy, mental health, and employment outcomes. J Speech Lang Hear Res. 2009;52:1401-16.

15. Shattuck PT, Narendorf SC, Cooper B, Sterzing PR, Wagner M, Taylor JL. Postsecondary education and employment among youth with an autism spectrum disorder. Pediatrics. 2012;129(6):1042-9.

16. Fink E, Deighton J, Humphrey N, Wolpert M. Assessing the bullying and victimisation experiences of children with special educational needs in mainstream schools: development and validation of the Bullying Behaviour and Experience Scale. Res Dev Disabil. 2015;36:611-9.

17. Rowley E, Chandler S, Baird G, Simonoff E, Pickles A, Loucas T, et al. The experience of friendship, victimization and bullying in 
children with an autism spectrum disorder: associations with child characteristics and school placement. Res Autism Spectr Disord. 2012;6(3):1126-34.

18. Riley AW, Spiel G, Coghill D, Döpfner M, Falissard B, Lorenzo $\mathrm{MJ}$, et al. Factors related to health-related quality of life (HRQoL) among children with ADHD in Europe at entry into treatment. Eur Child Adolesc Psychiatry. 2006;15(1):i38-45.

19. Sylvester J, Donnell N, Gray S, Higgins K, Stalker K. A survey of disabled children and young people's views about their quality of life. Disabil Soc. 2014;29(5):763-77.

20. Emerson E, Hatton C. Mental health of children and adolescents with intellectual disabilities in Britain. Br J Psychiatry. 2007;191(6):493-9.

21. Moss P, Howlin P, Savage S, Bolton P, Rutter M. Self and informant reports of mental health difficulties among adults with autism findings from a long-term follow-up study. Autism. 2015;19(7): 832-41.

22. Michael C. Why we need research about autism and ageing. Autism. 2016;20(5):515-6.

23. Brown KR, Peña EV, Rankin S. Unwanted sexual contact: students with autism and other disabilities at greater risk. J Coll Stud Dev. 2017;58(5):771-6.

24. Hirvikoski T, Mittendorfer-Rutz E, Boman M, Larsson H, Lichtenstein P, Bölte S. Premature mortality in autism spectrum disorder. Br J Psychiatry. 2016;208(3):232-8

25. Hallett S, Crompton CJ. 'Too complicated to treat'? Autistic people seeking mental health support in. Autistic Mutual Aid Society Edinburgh (AMASE): Scotland; 2018. www.amase.org.uk/ mhreport

26. Pellicano E, Ne'eman A, Stears M. Engaging, not excluding: a response to Walsh et al. Nat Rev Neurosci. 2011;12(12):769.

27. Salimi Y, Shahandeh K, Malekafzali H, Loori N, Kheiltash A, Jamshidi E, et al. Is community-based participatory research (CBPR) useful? A systematic review on papers in a decade. Int $\mathrm{J}$ Prev Med. 2012;3(6):386-93.

28. Pellicano E, Dinsmore A, Charman T. Views on researchercommunity engagement in autism research in the United Kingdom: a mixed-methods study. PLoS One. 2014;9(10): e109946 This survey and focus group study provides an evidence-based account of the obstacles to participatory research, with a specific remit to explore autism research in the UK but relevant more widely.

29. Pellicano E, Stears M. Bridging autism, science and society: moving toward an ethically informed approach to autism research. Autism Res. 2011;4(4):271-82.

30. den Houting J. Neurodiversity: an insider's perspective. Autism. 2019;23(2):271-3

31. Robertson SM. Neurodiversity, quality of life, and autistic adults: shifting research and professional focuses onto real-life challenges. Disabil Stud Q. 2009;30(1).

32.• Fletcher-Watson S, Adams J, Brook K, Charman T, Crane L, Cusack J, et al. Making the future together: shaping autism research through meaningful participation. Autism. 2019;23(4):943-53 This report on a UK-based seminar series presents a range of themes, illustrated by examples from research, policy and practice, pertaining to the continued evolution of participatory research practices.

33. Stack E, McDonald KE. Nothing about us without us: does action research in developmental disabilities research measure up? J Policy Pract Intellect Disabil. 2014;11(2):83-91.

34. Scott-Barrett J, Cebula K, Florian L. Listening to young people with autism: learning from researcher experiences. Int J Res Method Educ. 2019;42(2):163-84.

35. Long J, Panese J, Ferguson J, Hamill MA, Miller J. Enabling voice and participation in autism services: using practitioner research to develop inclusive practice. Good Autism Pract. 2017;18(2):6-14.
36. Fletcher-Watson S, Apicella F, Auyeung B, Beranova S, BonnetBrilhault F, Canal-Bedia R, et al. Attitudes of the autism community to early autism research. Autism. 2017;21(1):61-74.

37. Crane L, Adams F, Harper G, Welch J, Pellicano E. 'Something needs to change': mental health experiences of young autistic adults in England. Autism. 2019;23(2):477-93 This report on mental health in autistic youth provides a "best practice" example of inclusive research using a partnership model.

38.• Nicolaidis C, Raymaker D, Kapp SK, Baggs A, Ashkenazy E, McDonald K, et al. The AASPIRE practice-based guidelines for the inclusion of autistic adults in research as co-researchers and study participants. Autism. 2019;1362361319830523 This paper describes a practical guideline for the delivery of inclusive research practice, again developed in the field of autism research but relevant more widely.

39. Crompton CJ, Michael C, Fletcher-Watson S. Co-creating the autistic satisfaction with care holistic interview to examine the experiences of older autistic adults in residential care. Autism Adulthood. 2020;2(1):77-86.

40. Crompton CJ, Michael C, Dawson M, Fletcher-Watson S. Residential care for older autistic adults: insights from three multiexpert summits. Autism in Adulthood. 2020;2(2):121-7.

41. Cusack J, Sterry R. Your questions: shaping future autism research. London: Autistica; 2016.

42. Sibbald SL, Singer PA, Upshur R, Martin DK. Priority setting: what constitutes success? A conceptual framework for successful priority setting. BMC Health Serv Res. 2009;9:43. https://doi.org/10.1186/ 1472-6963-9-43.

43. Boote J, Barber R, Cooper C. Principles and indicators of successful consumer involvement in NHS research: results of a Delphi study and subgroup analysis. Health Policy. 2006;75(3):280-97.

44. Cowan K, Oliver S. The James Lind Alliance Guidebook. National Institute for Health Research Evaluation, Trials and Studies Coordinating Centre: Southampton, UK; 2013.

45. Pelton MK, Crawford H, Robertson AE, Rodgers J, Baron-Cohen $\mathrm{S}$, Cassidy S. A measurement invariance analysis of the interpersonal needs questionnaire and acquired capability for suicide scale in autistic and non-autistic adults. Autism in Adulthood. 2020;2(3): 193-203.

46. Cassidy SA, Bradley L, Cogger-Ward H, Shaw R, Bowen E, Glod $\mathrm{M}$, et al. Measurement properties of the suicidal behaviour questionnaire-revised in autistic adults. J Autism Dev Disord. 2020;50:3477-88.

47. Pelton MK, Crawford H, Robertson AE, Rodgers J, Baron-Cohen S, Cassidy S. Understanding suicide risk in autistic adults: comparing the Interpersonal Theory of Suicide in autistic and non-autistic samples. J Autism Dev Disord. 2020:1-18.

48. Bigby C, Frawley P. Reflections on doing inclusive research in the "Making Life Good in the Community" study. J Intellect Dev Disabil. 2010;35(2):53-61.

49. Burke A, McMillan J, Cummins L, Thompson A, Forsyth W, McLellan J, et al. Setting up participatory research: a discussion of the initial stages. Br J Learn Disabil. 2003;31(2):65-9.

50. Crane L, Goddard L, Pring L. Sensory processing in adults with autism spectrum disorders. Autism. 2009;13(3):215-28.

51. Liddiard K, Runswick-Cole K, Goodley D, Whitney S, Vogelmann E, Watts MBE, et al. "I was excited by the idea of a project that focuses on those unasked questions" co-producing disability research with disabled young people. Child Soc. 2019;33(2):154-67.

52. Peterson JC, Gubrium A. Old wine in new bottles? The positioning of participation in $17 \mathrm{NIH}$-funded CBPR projects. Health Commun. 2011;26(8):724-34 This qualitative analysis of grant proposals examines how community-based participatory research (CBPR) is positioned in the context of health research funding and reveals tensions between funder priorities and CBPR principles. 
53. Bauer GR. Incorporating intersectionality theory into population health research methodology: challenges and the potential to advance health equity. Soc Sci Med. 2014;110:10-7.

54. George R, Stokes MA. Sexual orientation in autism spectrum disorder. Autism Res. 2018;11(1):133-41.

55. Cooper K, Smith LG, Russell AJ. Gender identity in autism: sex differences in social affiliation with gender groups. J Autism Dev Disord. 2018;48(12):3995-4006.

56. Corbett $\mathrm{P}$, Corbett C. Missing out?: autism, education and ethnicity: the reality for families today: National Autistic Society; 2007.

57. Jo H, Schieve LA, Rice CE, Yeargin-Allsopp M, Tian LH, Blumberg SJ, et al. Age at autism spectrum disorder (ASD) diagnosis by race, ethnicity, and primary household language among children with special health care needs, United States, 2009-2010. Matern Child Health J. 2015;19(8):1687-97.

58. Liptak GS, Benzoni LB, Mruzek DW, Nolan KW, Thingvoll MA, Wade CM, et al. Disparities in diagnosis and access to health services for children with autism: data from the National Survey of Children's Health. J Dev Behav Pediatr. 2008;29(3):152-60.

59. West EA, Travers JC, Kemper TD, Liberty LM, Cote DL, McCollow MM, et al. Racial and ethnic diversity of participants in research supporting evidence-based practices for learners with autism spectrum disorder. J Spec Educ. 2016;50(3):151-63.

60. English R, Fenby-Hulse K. Documenting diversity: the experiences of LGBTQ+ doctoral researchers in the UK. Int J Dr Stud. 2019;14: 403-30.

61. Van den Brink M, Benschop Y. Slaying the seven-headed dragon: the quest for gender change in academia. Gend Work Organ. 2012;19(1):71-92.

62.• Stack EE, McDonald K. We Are "Both in charge, the academics and self-advocates": empowerment in community-based participatory research. J Policy Pract Intellect Disabil. 2018;15(1):80-9 This study reports on interviews with community members with developmental disabilities who have played collaborative roles in inclusive research and provides an important account of the non-academic partner perspective.
63. Parsons S, Yuill N, Good J, Brosnan M. 'Whose agenda? Who knows best? Whose voice?' Co-creating a technology research roadmap with autism stakeholders. Disabil Soc. 2020;35(2):20134.

64. McLaughlin H. Keeping service user involvement in research honest. Br J Soc Work. 2010;40(5):1591-608.

65. Black KZ, Hardy CY, De Marco M, Ammerman AS, Corbie-Smith $\mathrm{G}$, Council B, et al. Beyond incentives for involvement to compensation for consultants: increasing equity in CBPR approaches. Prog Community Health Partnersh. 2013;7(3):263-70.

66. Crompton CJ, Hallett S, Ropar D, Flynn E, Fletcher-Watson S. 'I never realised everybody felt as happy as I do when I am around autistic people': a thematic analysis of autistic adults' relationships with autistic and neurotypical friends and family. Autism. 2020;24(6):1438-48.

67. Yusuf A, Elsabbagh M. At the cross-roads of participatory research and biomarker discovery in autism: the need for empirical data. BMC Med Ethics. 2015;16(1):88.

68. Walsh P, Elsabbagh M, Bolton P, Singh I. In search of biomarkers for autism: scientific, social and ethical challenges. Nat Rev Neurosci. 2011;12(10):603-12.

69. Jivraj J, Sacrey LA, Newton A, Nicholas D, Zwaigenbaum L. Assessing the influence of researcher-partner involvement on the process and outcomes of participatory research in autism spectrum disorder and neurodevelopmental disorders: a scoping review. Autism. 2014;18(7):782-93.

70. Ward L. Funding for change: translating emancipatory disability research from theory to practice. In: Barnes C, Mercer G, editors. Doing Disability Research. Leeds: The Disability Press; 1998.

71. INVOLVE. Co-production in Action: Number One. INVOLVE: Southampton; 2019.

72. Autistica. Charles Sharland Scheme Report. London, UK: Autistica; 2021.

Publisher's Note Springer Nature remains neutral with regard to jurisdictional claims in published maps and institutional affiliations. 